Revista de la red interuniversitaria de estudios sobre las literaturas rioplatenses contemporáneas en Francia

21 | 2020

Glosolalias transplatinas: fantasmas, utopías y ficciones lingüísticas

\title{
El inconsciente teclado: la máquina de escribir en los idiomas inventados de Cortázar
}

L'inconscient dactylographié: la machine à écrire et les langues inventées de Cortázar

The Typed Out Unconscious: The Typewriter in Cortazar's Imaginary Languages Juan Cristóbal Castro

\section{(2) OpenEdition}

\section{Journals}

\section{Electronic version}

URL: http://journals.openedition.org/lirico/9636

DOI: $10.4000 /$ lirico.9636

ISSN: 2262-8339

\section{Publisher}

Réseau interuniversitaire d'étude des littératures contemporaines du Río de la Plata

\section{Electronic reference}

Juan Cristóbal Castro, «El inconsciente teclado: la máquina de escribir en los idiomas inventados de Cortázar», Cuadernos LIRICO [En línea], 21 | 2020, Publicado el 12 julio 2020, consultado el 29 enero 2021. URL: http://journals.openedition.org/lirico/9636 ; DOI: https://doi.org/10.4000/lirico.9636

This text was automatically generated on 29 January 2021.

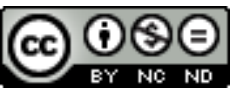

Cuadernos LIRICO está distribuido bajo una Licencia Creative Commons Atribución-NoComercialSinDerivar 4.0 Internacional. 


\title{
El inconsciente teclado: la máquina de escribir en los idiomas inventados de Cortázar ${ }^{1}$
}

L'inconscient dactylographié: la machine à écrire et les langues inventées de Cortázar

The Typed Out Unconscious : The Typewriter in Cortazar's Imaginary Languages

\author{
Juan Cristóbal Castro
}

\section{I}

1 Quizás podría parecer osado o equívoco de mi parte querer vincular el proyecto de Julio Cortázar de una lengua imaginaria, como el glíglico en Rayuela (2003) o el neofonema en El libro de Manuel (2004), con algo tan insignificante como puede ser la máquina de escribir y las prácticas que se abren con su uso. No lo niego, pues evidentemente hay otras influencias mucho más importantes sobre este asunto. Con todo, y sabiendo ese lugar marginal o secundario que podría ocupar el instrumento comercializado por primera ver por Christopher Sholes en la confección de estas creaciones verbales, no estaría mal atreverse a indagar un poco sobre la posible naturaleza de esta relación, si es que la hay, o si es que logro convencer a los lectores de estas líneas que pueda haberla. En ese sentido es clave tener en cuenta que ha podido darse, tanto de manera indirecta a través de algunos autores de la vanguardia que leyó el autor y que pensaron el medio, o bien de manera directa con la propia experiencia que tuvo con el aparato; no en balde Saúl Yurkiévich lo describía como una "máquina de escribir" (1999: 2), por no citar las múltiples referencias que hay en sus cuentos o cartas².

2 Partamos primero de lo evidente. Es muy clara la presencia recurrente de aparatos tecnológicos en la obra del cronopio mayor, tal como se llamó a sí mismo. Radios, teléfonos, televisores, salas de cine y proyectores se ven a lo largo de sus trabajos, cartas y cuentos. De igual modo, algunos de estos le sirven para pensar sobre la misma 
escritura, cosa que nos parece clave a la hora de hacer este análisis. Ya Jean Franco había advertido en "Comic Stripping: Cortázar in the Age of Mechanical reproduction" la toma de conciencia que vivió el autor en la era peronista de la cultura masiva (1998: 36-56). El fenómeno mediático de Perón y su esposa fueron también producto en cierto punto de una corriente abierta a partir de los años treinta y cuarenta, consecuencia del auge de diversos medios de comunicación y tecnologías: la radionovela y el cine sonoro, entre otros, fueron muy importantes en esos tiempos.

Entendiendo esto, habría que preguntarse cómo Cortázar piensa el lugar de la escritura literaria, y me parece que es fundamental el rol que juega aquí la Royal, la Olivetti Lettera 22, y sobre todo la Remington, medios que usó con dedicación. Además, desde Mark Twain la máquina de escribir es el instrumento por excelencia del escritor moderno. "Lo peor - confesaba Gabriel García Márquez- es que cuando uno se vuelve mecanógrafo esencial ya resulta imposible escribir de otro modo, y la escritura mecánica termina por ser nuestra verdadera caligrafía" (1982: 4). Este invento que, según Friedrich Kittler, "separa mano, ojo y letra en un momento que fue decisivo para la era de Goethe", ha sido decisivo para entender la escritura en el siglo XX (1987:195, mi traducción) ${ }^{3}$. Para Marshall McLuhan, la máquina de escribir ha acercado al escritor a los recursos de la imprenta y a sus posibilidades expresivas, además de convertir la experiencia de la escritura en actuación, es decir, una "especie de megafonía utilizable en el acto" ya que permite "gritar, susurrar o silbar, y hacer divertidos guiños tipográficos" (2009: 301). Los primeros de estos artefactos fueron hechos para ayudar a escribir a los ciegos, y de ahí que marquen una nueva relación entre la mano, el ojo y la escritura: la voz de la conciencia que dicta pasa ahora por las letras del teclado, que filtra este flujo sonoro y silencioso para terminar en las líneas estandarizadas de un papel. De hecho, el aparato le da más maniobrabilidad al creador moderno, al permitirle jugar de distintos modos con los efectos de sonoridad que produce el texto escrito ${ }^{4}$. Por la precisión que le da al formato escrito, la escritura puede romperse, yuxtaponerse, o abrirse a otras apropiaciones. Puede también crear nuevas combinaciones, disponiendo libremente del espacio en blanco, de la letra o de la tipografía. Gracias a esto se generan formas imprevistas de modulación y sonido a la hora de la lectura.

¿Cómo entonces ver una posible relación con los inventos verbales de Cortázar?

\section{II}

5 Un primer paso para descifrar esta relación consiste en rastrear la influencia del aparato sobre su poética estilística, especialmente en la confección de lo que podemos entender como lengua literaria, teniendo en cuenta que es fundamental para comprender la lógica en la que construye su glíglico y neofonema. En los cuentos del autor vemos aparecer el medio mecánico de diversas maneras. En "Las babas del diablo", que inspiró a Antonioni para hacer su película Blow Up, el traductor Roberto Michel tiene una vivencia particular con una cámara fotográfica, y no sabe cómo contarla usando su máquina Remington; lamentablemente tampoco puede dejarla libre para "escribir sola". "Nunca se sabrá cómo hay que contar esto, si en primera persona o en segunda, usando la tercera del plural o inventando continuamente formas que no servirán de nada" (1966: 77), nos dice el narrador. La experiencia de la temporalidad gramatical y sintáctica se fractura en varias vivencias que recrea en las fotos que ha 
tomado, una vez que las ha revelado y ampliado: el lugar de la enunciación se diluye. El sujeto de la escritura está aquí y allá al mismo tiempo. Es uno y muchos. Lo curioso es que el narrador sí cuenta la historia y desde la máquina puede estar en varias partes a la vez: en el lugar donde escribe, en el parque donde tomó las fotos, en la fotografía misma. Para ello, si bien no rompe totalmente con la gramática, porque no puede inventar un lenguaje donde pudiera decir: "yo vieron luna, o: nos me duele el fondo de los ojos" (1966: 78), sí arma un estilo propio, fiel a sus experimentaciones, que le sirven para crear una lengua literaria que permite describir un poco el suceso. De modo que desde la máquina puede perfectamente desdoblarse en varios e irrumpir en algunos lineamientos propios del orden sintáctico.

El otro cuento que quisiera mencionar no es menos revelador a este respecto. Se trata de "Allí, pero dónde, cómo" (1984: 25). El lugar de enunciación se da, como en las "Babas del Diablo", en el acto mismo de escribir a máquina. El narrador piensa y sueña sobre Paco, su amigo muerto, quien parece seguir vivo, al menos para el narrador. Cuando está escribiendo lo invaden recuerdos repentinos e inesperados. Esto es así por el mismo aparato, porque al mediar entre el ojo y la escritura en el papel permite suspender el control que intenta poseer la conciencia sobre el lenguaje articulado. Con ello logra un proceso de retardamiento y desvío que sirve para dar rienda suelta a la evocación fantasmática. En un fino contrapunteo tecnológico, la radio aparece para mostrarle la realidad, mientras que en el acto de escribir resucitan los tiempos muertos del pasado como si fueran actuales y como si fueran reales. De nuevo, la máquina sirve para revivir tiempos distintos al de la realidad, y a la vez (como nos propone el estilo literario del cuento) disloca la articulación de los enunciados, en ese estilo tan característico de Cortázar. Sin duda, estamos hablando de dos ejercicios: el de la lectura, que revive un tiempo que no está, y el de la inscripción escrita, que retarda y dispersa el orden de los enunciados y el control de la conciencia. Ambos son ejercicios propios de la escritura con la máquina de escribir que generan sin querer dispersión, fragmentación y diferimiento.

7 Finalmente, Cortázar nos da otra manera de entender este tema al comienzo de un texto que tiene un propósito político (2009a). El trabajo, producto de una ponencia que se presentó en un congreso de escritores en Cuba, muestra una incomodidad (algo escenificada, ciertamente) $)^{5}$. El autor argentino inicia con una digresión, que busca desviar las demandas que se ciernen sobre él como escritor serio, comprometido, que lleva el peso de una "autoridad". Se muestra allí como "perturbado" y describe cómo "destapa su máquina de escribir" y "retira los calcetines, esparadrapos, aspirina, comida para perros", productos que tienden a "acumularse en el hueco del teclado". Mientras escribe en ella cuenta cómo sonaba el teléfono cada dos minutos o cómo tenía dudas en la manera de escribir una ponencia (2009a: 251). En la escena no ocurre gran cosa, pero es importante destacar que, cuando el autor empieza a utilizar la máquina, de pronto comienza a incurrir en errores: dice "hadvertencia", o "himcomprensible", por ejemplo ${ }^{6}$. Entonces se comprueba que el aparato no solo es un instrumento para abrir nuevas posibilidades verbales que inscribe en su estilo de escritura, sino que lo conecta con una zona inconsciente de posibilidades altamente creativas (ese espacio del error, la sorpresa, el equívoco), y por fuera de esa demanda de seriedad, de compromiso, propio del mundo de los adultos intelectuales que él debe asumir y no asume. En él se opera entonces el desvío productivo, gracias al cual el autor puede acercarse a esa región incontrolable, donde no dominan los discursos racionales y 
donde se construye su particular ficción. Ahí descansan, a mi modo de ver, las fuentes de su experimentación verbal, de modo que para entender mejor la conexión entre la máquina y sus inventos lingüísticos creo determinante detenerme brevemente en este lugar, y me desvío un poco más en el análisis de las lenguas inventadas sólo para precisar mejor el terreno donde nos movemos ${ }^{7}$.

III

Si se considera la historia de cualquier aparato, se verá que, cuando su uso se naturaliza, toda reflexión sobre su soporte queda reprimida. Así, cuando se impuso la escritura a mano, el uso de la pluma y sus particularidades se dieron por descontado. Lo mismo podemos ver hoy en día con el computador; pocas son las personas a las que les interesa saber sobre el software que usa, o la modalidad de pantalla. Ahora, cuando se trata de una tecnología relacionada con la escritura alfabética, esta omisión termina siendo muchas veces doble: por un lado, se niega la mediación específica del aparato en sus lógicas de inscripción, y, por otro, se rehúye del ruido, molestia o interferencias que produce. Lo digo considerando cómo en Occidente siempre se ha privilegiado la voz pura y articulada del sentido frente al ruido de sus instancias específicas de registro, por no hablar de la tendencia a fetichizar la relación directa con el cuerpo, que trata siempre de negar los cambios y acoplamientos que debe desarrollar frente a los usos del nuevo instrumento.

Hago esta reflexión porque es precisamente esa región negada la que le interesa usar a Cortázar, y creo que su mirada a los medios procura acercarse a lo que Walter Benjamin una vez definió, para hablar de la cámara fotográfica, como "inconsciente óptico", pero que se puede usar también para hablar de otros artefactos tecnológicos. Me refiero a ese espacio de los sentidos y la imaginación que se abre en las posibilidades que prodiga cada tecnología, pero que no captamos por las limitaciones propias de nuestra percepción humana. Al hablar de la cámara, Benjamin resalta la capacidad que nos brinda de observar la postura de una persona en una fracción de segundo antes de alargar el paso, o "los aspectos fisiognómicos" de las cosas más pequeñas. Este nuevo horizonte de visibilidad se nos devela gracias al aparato tecnológico, que interviene "con sus recursos, el ralentí o el aumento". El campo de la visión se amplía drásticamente, vemos cosas nunca antes vistas y por eso "experimentamos el inconsciente óptico, igual que por medio del psicoanálisis nos enteramos del inconsciente pulsional" (2011:17).

10 Con la máquina de escribir sucede lo mismo. Como he citado antes a propósito de las reflexiones de McLuhan o Kittler, este artefacto propone nuevos acercamientos a la página escrita, que nos ayudan a incorporar a la escritura usos que no habíamos previsto: de la tipografía, de la letra impresa, del espaciamiento del texto, y sobre todo de la distribución de las palabras. Explorar estas novedades sin el control de las convenciones y protocolos del sentido cognoscente, racionalizador, del significado, es precisamente trabajar en esa zona del inconsciente tecnológico que suspende, demora o retarda el evento de la enunciación objetiva, de la frase articulada, de la proposición lineal, de la disposición ordenada de las sílabas y letras, rasgos contra los cuales se erige la lengua literaria de Cortázar, como hemos visto anteriormente. El automatismo de la escritura a máquina, si bien por un lado naturaliza una forma de escribir, por otro enajena al sujeto escribiente en esa despersonalización que muchos evocan, y por eso 
nos recuerda las técnicas de escritura de los surrealistas, tan aficionados a trabajar en esa zona del inconsciente. Al separar el cuerpo de la letra y la página e imponer una forma mecánica de escribir, permite una desconexión con lo que se escribe, gracias a lo cual surgen nuevas relaciones entre letras y sonidos, entre sílabas y frases. Despliega así una forma de producir frases sin saber lo que se dice que permite juegos combinatorios disímiles, entre los cuales podrían estar precisamente algunos de los fenómenos que dieron con lo que Cortázar llamó glíglico y neofonema, y ya con esto podemos entrar en materia.

\section{IV}

11 El glíglico que se utiliza en Rayuela de Julio Cortázar es acaso una de las invenciones que, junto con otros juegos y experimentos, resulta de gran atractivo para quien se acerca por primera vez a la obra. Nadie que no haya leído la novela podría dejar de conmoverse al llegar al capítulo 68, donde lo vemos en escena. También leer los momentos donde la Maga y Oliveira lo usan resulta en extremo placentero y divertido. Sin embargo, es muy extraño que Cortázar no haya hablado de él después; y que tampoco haya registro sobre su origen y naturaleza, como si se tratara de un secreto, o de algo con poca importancia; un juego más, de los muchos que ofrece la novela, sin duda, pero cuya naturaleza y genealogía nadie conoce lo suficiente. A falta de referencias al mismo, quisiera entonces concentrarme en algunos fragmentos, sin dejar de relacionarlos con su proyecto de una lengua literaria que el autor desarrolla en la novela. Uno de sus diálogos más importantes, que bien pudiera describir lo que he venido trabajando hasta ahora, sucede cuando la Maga y Oliveira se separan:

¿¿No querés que te siga contando de Ossip? -dio la Maga-. En glíglico.

-Me aburre mucho el glíglico. Además vos no tenés imaginación, siempre decís las mismas cosas. La gunfia, vaya novedad. Y no se dice "contando de".

-El glíglico lo inventé yo -dijo resentida la Maga-. Vos soltás cualquier cosa y te lucís, pero ese no es el verdadero glíglico (2003:221).

Como se sabe, el glíglico es la lengua que usan ambos y que en cierta manera encarna su relación particular de amor, que no es para nada convencional. Se trata de un uso arbitrario de las sílabas y los sonidos, que remite por otro lado a ciertas formas de la oralidad argentina. Es lógico que, al separarse de la Maga, Oliveira ya no quiera seguir jugando: no encuentra en ella el viejo hechizo o complicidad que antes tenía. Y es que esta lengua inventada, de alguna manera representa una de las formas del personaje principal para subvertir el orden social. El protagonista desconfiaba de las palabras y estaba todo el tiempo inventando "juegos" para deshacerse de sus convenciones. Es cierto que en el fragmento se nos dice que es la Maga quien lo inventa, aunque no deja de estar vinculado con las exploraciones de Oliveira. No es casual que la propia novela se embarque también en este proyecto: rayuela es un juego de niños y Morelli, parafraseando al protagonista, decía: "si seguimos utilizando el lenguaje en su clave corriente, con sus finalidades corrientes, nos moriremos sin haber sabido el verdadero nombre del día" (2003:614). Paralelamente la obra desarrolla otros experimentos a lo largo de sus páginas ${ }^{8}$, pero ya en el mismo capítulo 68, vemos en acción el idioma inventado del glíglico:

Apenas él le amalaba en el noema, a ella se le agolpaba el clémiso y caían en hidromurias, en salvajes ambonios, en sustalos exasperantes. Cada vez que él procuraba relmar las incopelusas, se enredaba en un grimado quejumbroso y tenía 
que envulsionarse de cara al nóvalo, sintiendo cómo poco a poco las arnillas se espejunaban, se iban apoltronando, reduplimiendo, hasta quedar tendido como el trimalciato de ergomanina al que se le han dejado caer unas fílulas de cariaconcia.

(2003:533)

13 Varias cosas merecen destacarse de estas citas. El idioma parte de una base española; si se eliminan las palabras sin sentido, lo que queda muestra claramente el soporte de una gramática y sintaxis castellana, una especie de parergón. Además, vale decir, que la retórica y el estilo de este marco es formal, en un estilo del español simple y poco rebuscado. Si nos desprendemos de las palabras inventadas del anterior extracto, nos encontramos con lo siguiente:

Apenas él le......a ella se le....y caían en....Cada vez que él procuraba....se enredaba en....y tenía que....sintiendo cómo poco a poco....se iban....hasta quedar tendidos como el... al que se le han dejado caer unas (2003:59) ${ }^{9}$

Allí se conserva entonces la base sintáctica del castellano. El cambio, o la provocación verbal, se presenta sólo a nivel del léxico, lo que corrobora no sólo el hecho de que estas lenguas imaginarias surgen después de la consolidación de la lengua española dentro de las instituciones latinoamericanas, sino que además son fieles a la linealidad de la escritura, cosa que se va a consolidar por cierto con la máquina. Al ver bien esto, podemos especular que estas transformaciones pueden ser recreadas gracias al uso libre del aparato. Es verdad que el glíglico de Cortázar revive las trazas de intentos anteriores por crear una lengua distinta al español, al igual que recoge y reinscribe ciertos dialectos marginados por el idioma oficial del Estado. Es claro también que este idioma es una de las diversas expresiones que usa Oliveira para rebelarse contra la estructura del significado, contra la construcción del lenguaje convencional y pragmático, propio de la racionalización de la vida burguesa. Eso no lo dudo. Pero es bueno tomar nota de que combinaciones como "amalababa", "ambonios", "clemiso" o "sustalos" muestran variaciones en las sílabas y letras que bien nos recuerdan los errores que producen las máquinas, errores productos a su vez de cierto uso inconsciente de la misma. Recordemos que Cortázar usó la Olivetti Lettera 22 para escribir Rayuela y se sabe que lo hacía sin plan alguno sobre el teclado, dejándose llevar por las palabras del medio. ${ }^{10}$ ¿No puede haber ahí un signo importante?

Por eso, al acercarnos a algunas cartas de Cortázar, podemos ver algunos indicios de lo que digo. En ellas la máquina de escribir desvía, rompe, retarda, no solo la temporalidad, sino también la demanda lógica de las palabras como estructura articulada entre sílabas. Así, en la misiva a su amigo Jonquières fechada en París el 9 de julio de 1954, antes de escribir Rayuela, habla de "lanzarse al galope" al dejarse llevar por el artefacto, gracias al haber suspendido su labor en el trabajo, al haber hecho un alto; y como correlato de esta liberación, está también el hecho de asumir un "tono casi oral", muy propio de su estilo literario. Esto es posible por la velocidad de la escritura con la máquina eléctrica que usaba para ese entonces, pues se reduce el lapso entre el pensamiento y la enunciación por escrito de las palabras. De ahí que en esa misma epístola incurra en errores, como "embajadotrabajos", ya que "los peores juegos de palabras pueden nacer del pobre ingenio de una máquina de escribir" (2010:230). Precisamente esta confesión de que las combinatorias verbales puedan surgir de este aparato nos da claves importantes. Dejarse llevar por la máquina es suspender toda voluntad consciente de sentido y supeditarse a las maniobras y atributos de los que goza la tecnología. Es perderse, entrar en otra zona, en otra región. “El inconveniente 
de escribir a máquina es que uno pierde el hilo", decía Kafka en una de sus cartas a Felice (1977: 44).

En El diario de Andrés Fava (1995) se encuentra el primer testimonio en clave ficcional de la búsqueda verbal de Cortázar, un texto muy revelador que marca la presencia de la máquina de escribir. En él se habla de un Carnaval en el que se le ocurrió escribir un relato a "vuela-máquina" donde se da una "sumisión total a la mecánica" que significa también sumisión a la poesía "a la forma en que esta irrumpe y se da", y así "deshacer la horizontalidad sucesiva" y de un "salto desparramar, salpicar en el papel lo que, realmente, era un coletazo de ola, una vivencia global" (1996:54). Creo que es evidente lo que se dice allí: el escribir a "vuelamáquina" muestra que su búsqueda ya estaba determinada por "la sumisión total a la mecánica", que lo lleva entonces a "deshacer la horizontalidad sucesiva" de la manera como se agolpan, se reúnen y distribuyen las palabras, pero también, podríamos decir, las sílabas mismas, las relaciones entre vocales y consonantes. Por ello no es difícil darse cuenta de que la realidad material y tecnológica tuvo una gran influencia, tal como le sucedió a los autores que tanto leyó (Joyce, Mallarmé, gran parte de los escritores de vanguardias, el grupo Oulipo, Borges, Girondo o Michaux), en la confección y construcción de una lengua literaria; y, como venimos sosteniendo, la máquina de escribir puede perfectamente servir para facilitar estas desconexiones entre frases, sílabas y palabras. Si bien a partir de la Remington, se pudo ver mejor la página, el protagonismo de la tecla visibilizaba sólo la letra y su distribución en el teclado permitía nuevas combinaciones. Es verdad que con ella se reprodujo e impuso más la linealidad de la escritura, desde sus usos convencionales, lo que no significaba que evitara distribuciones entre sus signos de manera más aleatoria.

Por último, y volviendo a la carta de su amigo, podemos dar cuenta de cómo al usar la máquina participa en una escenificación de juegos verbales, tan característicos en su estilo literario. Por eso le manda a Jonquières "crefundeos" (palabra inventada por el pintor Adolfo Ollavaca) para denominar sus poemas, y juega con las palabras con afirmaciones que no terminan: "Volviendo a los pasajes, te pido pues ENKARESIDAMENTE que les aclares a los navifrancos (Gue" (2010:255). En otra expresa: "Dunque, auguri y a poner a punto la mvestra (si no entendés esta palabra pedile a Glop que te explique mis manías verbo ortográficas)" (2010: 281).

Con el neofonema vemos, sin duda, otra cosa. Si bien hay algunos elementos en común con el glíglico, eso sólo es en apariencia, porque visto en perspectiva nos daremos cuenta de que sobresalen muchas diferencias. Lonstein ("el rabinito") es su creador, y no tiene ninguna Maga a la cual dedicar sus juegos verbales; por el contrario, sólo tiene la soledad de su imaginación onanista. Este personaje, que bien pudiera verse como una versión demacrada de Oliveira -que ya estaba bien demacrado, por cierto- es uno de los integrantes de la Joda que, al igual que el Club de la serpiente en Rayuela, es un grupo de jóvenes inmigrantes, críticos de la burguesía y sus convenciones sociales, culturales, y, por supuesto, verbales. Esta agrupación se diferencia, eso sí, de los amigos de la Maga, porque son la mayoría latinoamericanos, militantes de izquierda, que se encuentran conspirando en contra de los gobiernos fascistas de derecha y de las dictaduras que están dándose en esos momentos en América Latina. A la vez, muchos de ellos se encuentran perseguidos por las hormigas, que son integrantes de los servicios secretos de los regímenes contra los cuales luchan. De modo que, en esta novela, se introduce el tema político desde la militancia, el radicalismo, la violencia. 
Es por eso que el Libro de Manuel es un texto altamente politizado, con claros rasgos de denuncia. La lengua de Lonstein no se escapa de ello. La crítica implícita que lleva sobre las convenciones verbales de la sociedad se hace más explícita que en el glíglico, que también era una lengua que se oponía a las imposiciones de los mayores. Sin embargo, se trata de un idioma inventado cuya base es individual, muy cercano a su inventor y las peculiaridades de su personalidad: judío argentino, exiliado de su país, criollo. Así uno de los personajes dice: “...lo de las palabras made in Lonstein nunca fueron juego aunque nadie hubiera podido saber a qué tendían, defensa o agresión, para mí contenían de alguna manera la verdad de Lonstein" (2004: 36). Al parecer se trata de una lengua con varias derivaciones, entre ellas el "boex", que consiste en siglas. Así, la palabra "fortrán" es un "término significante en el lenguaje simbólico del cálculo científico", es una "formulación transpuesta", que "economiza los fonemas". "Con estos métodos sintetizadores, es decir mesín, se avanza veloz y económicamente hacia la organización lógica del cualquier programa, o sea el orlopró", señala (2004: 226).

En esta derivación del neofonema se puede advertir la lógica que gobierna este idioma, que sigue fiel al proyecto de Cortázar de poner en cuestión toda forma de lenguaje instrumental, pues se trata "de una lenguaje simbólico que se puede aplicar más allá o más acá de las ciencias" (2004: 227), y de una "organización ilógica de cualquier programa" (2004: 227). El hecho de que esté constituido por siglas o acrónimos nos puede remitir a la idea de códigos ocultos que deben descifrarse y esconderse, es decir, son formas de un idioma secreto propio del espionaje, de la lógica de la guerra, pero también de una era marcada por la cibernética, que nació precisamente queriendo descifrar mensajes desconocidos con el invento de Alan Turing. La sigla, que es un conjunto de palabras conformadas por las letras iniciales de otras palabras, viene del latín y significa cifra. Para Kittler este término se usó a partir de la Edad Media tardía para designar lo que se llama código, que volvió operacional, numérico, el lenguaje alfabético en tiempos informáticos, en el que la máquina de escribir, gracias al uso del teclado, fue un importante precedente (No hay Software, 24). No por casualidad la famosa Olivetti que utilizara Cortázar produjo el primer ordenador que se conozca en Italia, el Elea 9003 en 1959, y además fue precursora de los primeros modelos personales con el Programa 101, que se vendieron a la NASA, usado también por el sistema de la fuerza aérea norteamericana para bombardear en la Guerra de Vietnam.

En un momento de El libro de Manuel, hasta se escribe un poema con esta lengua:

Buscá ecofón con un mesín

pero que nunca una fortrán

falte a la cita, si querés

un orlopro de gran coherencia

¡Boex! (2004: 227)

Por lo que se puede ver en el poema, y en las reflexiones de Lonstein, no es difícil ver ciertos elementos que ya hemos mencionado anteriormente. Primero, es un idioma que busca economizar las palabras con las famosas siglas. Segundo, no pretende cambiar la gramática y convive con usos del argentino coloquial ("buscá"). Y, tercero, es una lengua cuyo programa de cambio se concentra sobre todo en el léxico, aunque haya una que otra variante en el orden sintáctico. Así vemos cómo esta lengua inventada, más allá de las diferencias con el glíglico, brinda posibilidades combinatorias muy cercanas a las que posibilita la máquina de escribir con el juego de las letras y signos, manteniendo la linealidad de la frase y la estructura gramatical, como si en el fondo 
fueran parte de ese juego con el instrumento que revela el autor en sus cartas al amigo Jonquières.

Sabemos que la máquina misma es ambigua. Es cura y veneno a la vez, peligro y salvación, herida real y emancipación potencial. Reprime y libera, corta, interrumpe y establece puntos de fuga: abre y cierra. Es verdad que Cortázar explora un territorio inconsciente en ella, una región no prevista por las tecnologías anteriores que han naturalizado prácticas hermenéuticas propias de lo que entendemos como sentido, pero no hay que olvidar que esto puede suceder por un elemento de este aparato que no deberíamos dejar de lado. La Remington, la Olivetti o la Underwood también han servido para serializar y estandarizar la escritura a dimensiones nunca antes vistas, y se han convertido en un dispositivo muy importante de control social, usado en la burocracia estatal y empresarial para registrar documentación clasificada, para ordenar historias personales, para regular conductas y comportamientos. La oficina moderna no sería lo que es hoy en día sin la participación de las máquinas, así como los archivos de finales del siglo XIX y comienzos del XX. Ya en 1876, según James R. Beninger, su uso era una "innovación básica para proveer la información dentro del aparato burocrático" (1986: 283). Más adelante, a partir de 1920, se convierte en equipo estándar para la mayoría de las agencias e instituciones gubernamentales (archivos, oficinas, departamentos) en Europa y Estados Unidos ${ }^{11}$.

El trabajo que el cronopio mayor, para regresar a Cortázar, llevó a cabo en la Unesco en su estancia parisina muestra claramente el grado de conciencia que tenía de esta realidad. En una carta, fechada el 6 de junio de 1955, cataloga su trabajo allí como "pedestre y aburrido"; y confiesa que "estar solo aquí es una especie de infierno doméstico y tonto", porque no hay "camaradería" (2010: 314). En otra misiva, meses después, dice que "se pierde la cuenta de los días, tan iguales son unos a otros" (2010:307). Esta resistencia al lugar y su labor monótona también se proyecta al tipo de máquinas de escribir que usa y que lo lleva a cometer "horrores tipográficos" (2010: 337). Casi diez años después, desde Ginebra, expresa en francés que el instrumento "a l'inconvénient de la perfection" (2010: 448) y decide escribir en varios idiomas, jugando con los mismo errores, que nos muestran una vez más este vínculo entre el aparato y sus experimentaciones verbales: "un flottement inépuisable de la pensé qui voudrait exprimer une chose et en exprime une autre : mais, ne serait-ce pas cela la Poêêêêsie" (2010: 448).

En cierta medida, el niño subversivo que critica el orden de los adultos, se vale de este instrumento como un juguete peligroso que pone en jaque las convenciones del poder. Por eso en muchas ocasiones busca romper con los protocolos que homogeneizan la práctica de la escritura a máquina: uso de la ortografía, del interlineado, de las sangrías, de la distancia entre párrafos o entre letras, de la disposición de las mayúsculas o del tipo de letra. En consecuencia, y ya para terminar, la gestación del glíglico y el neofonema puede inscribirse, sin desestimar otras influencias, en este programa que busca descolocar los usos estandarizados de la máquina de escribir, explorando su potencial creativo en esa zona inconsciente donde se dan los errores productivos, las combinaciones azarosas y por supuesto las relaciones inesperadas. Con esto aspiro arrojar alguna luz sobre la posible relación de este instrumento tan curioso, como lo fue la máquina de escribir, con los idiomas inventados de Cortázar. 


\section{BIBLIOGRAPHY}

Cortázar, Julio, “Allí, pero dónde, cómo”, Octaedro, Buenos Aires, Sudamericana, 1974.

---, El Examen, Madrid, Alfaguara, 1986.

---, Divertimento, Bogotá, Oveja Negra, 1987.

---, Obra crítica 1, Madrid, Alfaguara, 1994.

---, El Diario de Andrés Fava, México, Alfaguara, 1995.

---, Rayuela, Madrid, Cátedra, 2003.

---, Libro de Manuel, Barcelona, Punto de Lectura, 2004.

----,"El creador y la formación del público”, Papeles inesperados, Madrid, Alfaguara.

2009a, p. 254-270.

---,“Como Lucas para equivocarse en la máquina es un as”, Papeles inesperados, Madrid, Alfaguarda, 2009b, p.138-142.

---, Carta a los Jonquières, Madrid, Alfaguara, 2010.

Albani, Paolo y Berlinghiero Buonarroti, Dictionnaire des Langues Imaginaires, París: Belles Lettres, 2001.

Benjamin, Walter, Breve historia de la fotografía, Madrid, Casimiro, 2011. Traducción de Wolgang Erger

Eco, Umberto, La búsqueda de la lengua perfecta, Barcelona, Grijalbo Mondadori, 1996. Traducción de María Pons.

Franco, Jean, “Comic Stripping: Cortázar in the Age of Mechanical Reproduction”, Julio Cortázar, New Readings, 1998, p.36-56.

García Márquez, Gabriel, "El amargo encanto de la máquina de escribir”, El País, 7 de julio 1982.

Mcluhan, Marshall, Comprender los medios de comunicación: Las extensiones del ser humano, Barcelona, Paidós, 2009.

Traducción de Patrick Ducher.

Kafka, Franz, Cartas a Felice, Madrid, Alianza, 1977. Traducción de Pablo Sorozábal Serrano.

Kittler, Friedrich, Discourse Networks 1800/1900, Stanford, Stanford University Press, 1987. Traducción de Michael Metter y Chriss Cullens.

---, Gramaphone, Typewriter, Stanford, Stanford University Press, 1986. Traducción de Geoffrey Winthrop-Young y Michael Wutz.

---, No hay software y otros ensayos, Caldas, Universidad del Caldas, 2017. Traducción de Mauricio González Roso.

Olson, Charles, "Projective Verse and and Letter to Elaine Feinstein", Selected Writings. New York, Penguin Books Canada, 1967, p.15-30.

Pérez Salazar, Juan Carlos, “Mario Vargas Llosa: 'Me gustaría que la muerte me hallara escribiendo, como un accidente”, BBC: News Mundo, 29 Mayo 2019, Web. Consultado 10 Diciembre 2019. 
Rodeiro, Martín, "Xul. Más allá del idioma (de los argentinos)", Beligerancia de los idiomas: Un siglo y medio de discusión sobre la Lengua Latinoamericana, Buenos Aires, Colihue, 2008, p. 185-253.

Schwartz, Jorge, (ed.), Las vanguardias latinoamericanas: textos programáticos y críticos. Madrid, Cátedra, 1991.

---,"Utopías del lenguaje: nuestra ortografía bangwardista”, Lectura crítica de la literatura americana: vanguardia y tomas de posesión, Caracas, Biblioteca Ayacucho, 1997, p.23-85.

Tolkien, J.R.R, “A Secret Vice.”, The Monsters and the Critics and Other Essais, Londres, George Allen\&Unwin, 1983, p.42-67.

Yaguello, Marina, Les fous du langage: des langues imaginaires et de leurs inventeurs, Paris, Editions du Seuil, 1984.

---, Lunatic Lovers of Language: Imaginary Languages and their Inventors. Londres, The Athlone Press, 2001.

Yurkievich, Saúl, A través de la trama: sobre vanguardias literarias y otras concomitancias, Barcelona, Muchnik,

1984.

Rosenzvaig, Marco, “Entrevista a Saúl Yurkievich, el albacea de Julio Cortázar”, Globedia, 18 Mayo 2013, Web. Consultado el 15 diciembre 2019.

\section{NOTES}

1. Este texto es parte de una reflexión que vengo trabajando en el libro Idiomas espectrales y en un trabajo que recientemente publiqué para la revista Transas, titulado "La tecla inespecífica: la máquina en la literatura latinoamericana en el siglo XX". De paso, quiero agradecer las conversaciones con Mario Cámara, Gonzalo Aguilar, Florencia Garramuño y Cecilia Rodríguez sobre el tema.

2. Al parecer, Cortázar usaba en sus primeros momentos en Argentina la máquina Royal; uno de sus cuentos de ese periodo, "Carta a una señorita en París", de hecho la menciona. Pero ya para los años sesenta cambia a la Remington, un modelo clave para la propuesta que pretendo desarrollar en estas líneas, por no hablar de su famosa Olivetti Lettera 22 que usó con mucha regularidad durante gran parte de su vida.

3. "unlinks hand, eye, and letter within the moment that was decisive for the age of Goethe".

4. Sobre esto, el poeta Charles Olson señala: "It is the advantage of the typewriter that, due to its rigidity and its space precisions, it can, for a poet, indicate exactly the breath, the pauses, the suspensions even of syllabes, the juxtapositions even of parts of phrases, which he intends" (1967: 22).

5. Hay que tomar en cuenta que el contexto de la intervención es, para tomar una posición, complicado con respecto a lo que viene sucediendo en Cuba, así que era muy sugerente para Cortázar jugar a las desviaciones. Si bien en el texto este lugar de la máquina es dramatizado, convirtiéndose en retórica, no deja de ficcionalizar esa posibilidad que genera la interacción con el medio. Debo esta observación al encuentro que tuve en el Instituto de Literatura Hispanoamericana de la UBA, organizado por María Fernanda Pampín. 
6. El error tiene en la escritura un poder liberador. Este mal también nos recuerda a Lucas cuando lidia con el tema de las erratas: "Como Lucas para equivocarse en la máquina es un as", nos dice el narrador y después nos muestra numerosos equívocos (2009b:138).

7. Para una revisión de las lenguas inventadas en la literatura están en la bibliografía textos de Tolkien, Yaguello, o Eco. Sobre el tema en América Latina están los trabajos de Schwartz, o Rodeiro, entre otros.

8. No es casual que uno de ellos reviva el proyecto verbal de una ortografía fonética, elaborado por el grupo que editó la revista mexicana Renovigo; junto a él, también se encuentran los usos coloquiales de los personajes, que reviven palabras del lunfardo y el cocoliche. De igual modo, están los múltiples casos donde se busca violentar la ortografía: Oliveira, por ejemplo, en el capítulo noventa, cavilando sobre su situación con la Maga, decide escribir irrespetando las reglas ortográficas, agregando la letra $h$ a cuanta palabra podía.

9. Tomo este fragmento del desglose que hace Andrés Amorós, editor de la novela de Cortázar en Cátedra, quien en la introducción al mismo muestra este trasfondo castellano del texto (2003:59).

10. Mario Vargas Llosa recordaba en $B B C$ : News Mundo cómo Cortázar al escribir Rayuela se sentaba a escribir sobre la máquina sin plan predeterminado, tal como Kerouac hacía con su culto a la improvisación. (2019 Web).

11. Nada más evidente de este fenómeno que las reflexiones que Kafka, escritor por excelencia de la modernidad, hace en muchas de sus cartas. A Felice Bauer, luego de reflexionar sobre la imposibilidad de trabajar de manera autónoma, le confiesa: “....me siento tan atraído a la máquina de escribir en todos los asuntos relacionados con la oficina, pues su trabajo -realizado, además, por la mano del mecanógrafo- es tan anónimo" (1977: 193). Por tanto no es difícil interpretar el cuento "En la colonia penitenciaria" como una alegoría de la máquina de escribir, como han señalado varios críticos: el aparato de tortura escribe sobre el cuerpo de la persona, inscribe en él letras tipográficas.

\section{ABSTRACTS}

This article concerns the origins of Cortázar's imaginary languages as a resullt of the use of the typewriter. Following the proposals of some theorists (Kittler, Mcluhan, Olson), as well as the works and personal letters of the Argentine writer, I would like to construct the tentative line of influence that led him to think about some of his fictional languages.

Me gustaría pensar la posibilidad de considerar los orígenes de las lenguas imaginarias de la obra de Cortázar como producto de ciertas reflexiones y prácticas que le brindó el uso de la máquina de escribir. A partir de las propuestas de algunos teóricos (Kittler, Mcluhan, Olson), así como de una exploración cuidadosa en la obra y las cartas del escritor argentino, me gustaría construir una tentativa línea de influencia que lo llevó a pensar en la conformación de algunos de sus idiomas inventados.

L'article s'interroge sur les origines des langues imaginaires dans l'œuvre de Cortázar, liées à l'utilisation de la machine à écrire. À partir des propositions théoriques de Kittler, Mcluhan, Olson et autres, je voudrais parcourir l'œuvre et la correspondance de Cortázar, suivant la ligne d'influence qui l'a aidé à penser et à fabriquer certaines de ses langues imaginaires. 
INDEX

Mots-clés: Langues, imaginaires, machine, mots, écriture

Palabras claves: lenguas, imaginarios, máquina, palabras, escritura

Keywords: languages, imaginaries, machine, words, writing

\section{AUTHOR}

JUAN CRISTÓBAL CASTRO

Pontificia Universidad de Católica Valparaíso

chozac@hotmail.com 